\title{
Implantation Classification Supplemental Qualifiers Dataset
}

National Cancer Institute

\section{Source}

National Cancer Institute. Implantation Classification Supplemental Qualifiers Dataset. NCI Thesaurus. Code C147217.

A dataset containing supplemental information, specifically non-standard variables, to parent records in the implantation classification domain. 